\title{
Correction to: Influence of Multiple Earthquakes on Single-Layer Reticulated Dome and Its Shaking-Table Test
}

\author{
Ying-Nan Zhang ${ }^{1,2,3} \cdot$ Xu-Dong Zhi ${ }^{1,2,3} \cdot$ Feng Fan $^{1,2,3}$
}

Published online: 1 February 2020

c) Korean Society of Steel Construction 2020

\section{Correction to: International Journal of Steel Structures https://doi.org/10.1007/s13296-019-00272-w}

In the original publication of the article, data of maximum nodal displacement were published incorrectly in few places. The correct data are provided below.

Under the section 5.6 Verification of Four AftershockInfluence Levels, data of maximum nodal displacement in the following sentence were published incorrectly as, “... stiffness still remains good, with only $L / 456$ as the maximum nodal displacement. Under condition 16, the...." The correct sentence should read as "...stiffness still remains good, with only $L / 1368$ as the maximum nodal displacement. Under condition 16 , the...."
The original article can be found online at https://doi.org/10.1007/ s13296-019-00272-w.

Xu-Dong Zhi

zhixudong@hit.edu.cn

1 Key Laboratory of Structural Engineering Disaster Control of Education Ministry (Harbin Institute of Technology), Harbin 150090, China

2 Key Laboratory of Civil Engineering Intelligent Disaster Prevention and Mitigation Control of Ministry of Industry and Information (Harbin Institute of Technology), Harbin 150090, China

3 School of Civil Engineering, Harbin Institute of Technology, Harbin 150090, China
In addition, data of maximum nodal displacement in the following sentence were published incorrectly as “... The structural stiffness reduces a lot, with many visibly bent tubes, and the maximum nodal displacement reaches $L / 199$. Under condition 20, the model topples." The correct sentence should read as "...The structural stiffness reduces a lot, with many visibly bent tubes, and the maximum nodal displacement reaches $L / 597$. Under condition 20, the model topples."

Finally, data of maximum nodal displacement of Table 7 were published incorrectly. The correct version of Table 7 is provided below. 
Table 7 Structural state from condition 8 to condition 20

\begin{tabular}{lllll}
\hline Condition & $\begin{array}{l}\text { Maximum nodal displace- } \\
\text { ment of VD1 }(L: \text { span })\end{array}$ & $\begin{array}{l}\text { Existing deformed } \\
\text { tubes or not }\end{array}$ & $\begin{array}{l}\text { Ratio of yield } \\
\text { members }(\%)\end{array}$ & Structural state \\
\hline 8 & $1 / 2469$ & No & 0 & Elastic \\
10 & $1 / 3429$ & No & 0 & Elastic \\
12 & $1 / 1848$ & No & 0 & Elastic \\
14 & $1 / 1368$ & No & 8.33 & Slightly plastic \\
16 & $1 / 774$ & Yes & 22.22 & Slightly plastic \\
18 & $1 / 597$ & Yes & 59.72 & Significantly plastic \\
20 & - & - & - & Collapse \\
\hline
\end{tabular}

Publisher's Note Springer Nature remains neutral with regard to jurisdictional claims in published maps and institutional affiliations. 